\title{
LAS OSCILACIONES DEL PRECIO DEL TRIGO EN UNA CIUDAD DEL LEVANTE: EL CASO DE MURCIA, 1675-1800
}

C. CARO LOPEZ

Pósito, Almudi, Alholí, tres nombres distintos para una institución•que, en palabras de Anes, «fue costumbre inmemorial en nuestro país, de la que dan constancia los fueros municipales»' '. Castillo de Bobadilla, que se remontaba al Génesis para hallar huella de su existencia, aseguraba que

«assí como a los padres toca alimentar a los hijos, assí a los Corregidores que son llamados padres de la República, toca alimentar a los vezinos» ${ }^{2}$.

La rẹglamentación de estos importantes instrumentos de la administración ciudadana se convierte gradualmente en materia importantísima por la trascendencia de sus funciones; así, la Novísima Recopilación recoge la legislación en su título XX del libro VII, legislación que demuestra cómo el abasto público siempre ha sido importante en la mente de los gobernantes ${ }^{3}$.

A los regidores murcianos no debieron de faltar estas y otras razones para prestar particular cuidado a la administración de un recurso tan valioso como el trigo. Seguramente no compartirían la exagerada visión de Espinalt ${ }^{4}$, y lo cierto es que la acción del Pósito fue constante durante toda la Edad Moderna, hasta bien entrado el siglo xIX. Es evidente:

«importava mucho que el caudal del Pósito fuese quantioso para hazer grandes empleos de trigo que sirviesen en el tiempo mas nezesitado del año que era desde el mes de marzo en adelante asta aver coxido la Cosecha nueva para asegurar el avasto del pan

' Anes (1968, 1970).

- Castillo de Bobadilla (1704), p. 24.

'Novísima Recopilación (1805). Véase también, para Murcia, el estudio de Flores Arroyuelo (1977).

- Murcia, жen medio de una amena Vega, que sus naturales llaman la Huerta, tan fértil, que muchos años rinde en pan ciento por uno». Espinalt (1778), p. 9. 
en dicho tiempo que es el de mas consumo por venir en el a esta tierra de la Mancha y otras partes mucho numero de gente a la cria de la sedas ${ }^{5}$.

Riquísima la documentación de que disponemos para estudiar la dinámica de los precios vendidos por el Pósito del Pan. Los registros de Acuerdos Capitulares mencionan en sus respectivas sesiones las posturas tomadas por el Cabildo sobre precios y ventas, y, además, como fuente de integración de estos datos, se conservan en el Archivo Municipal de Murcia varios legajos de la administración del Pósito. Estos documentos, que no forman una serie completa, son, sin embargo, muy interesantes, pues recogen las cuentas oficiales de los ejercicios económicos -que duraban desde San Juan de un año hasta la misma fecha del siguiente - y han sido siempre preferidos a las fuentes capitulares. Además, en ellos se conservan las actas de varias juntas del Pósito, comisiones en las que el consejo ciudadano delegaba - sobre todo en momentos de crisis de abastos - la tarea de discutir y fijar la política anonaria. Salvo en poquísimas ocasiones, y probablemente debido a descuidos de los escribientes, los datos de los libros de acuerdos capitulares coinciden con los legajos del Pósito; en caso de discrepancia, se han preferido por su carácter técnico los de la administración del Almudí ${ }^{6}$.

Con estos datos se han obtenido series de los precios del trigo vendido en el Pósito de Murcia; el gráfico 1 recoge el desarrollo de dichos precios expresados en reales por fanega, y se refiere al trigo que la administración ciudadana ponía a disposición de los panaderos. Se ha indicado el precio medio anual de cada temporada agrícola, esto es, el período incluido entre primero de agosto y último de julio de cada año, para no mezclar la influencia de dos cosechas distintas ${ }^{7}$. Las cifras que se dan han sido calculadas en base al precio medio mensual del trigo, primero, y después a la media de precios de los meses durante los que estuvo en venta al público. De esta manera se han desechado los años para los que no hay suficientes datos, o sea, cuando los precios se refieren a demasiados pocos meses como para establecer un valor indicativo. Así, aunque las series no sean continuas, todos los datos son absolutamente fiables. Se ha intentado, por otra parte, seguir lo explicado por Anes y Le Flem al elegir las representaciones gráficas «más fieles», que se obtienen

Archivo del Ayuntamiento de Murcia (AAM), Acuerdos Capitulares (en adelante, AA. CC.), 5-XI-1695.

- AA. CC., años de 1671 a 1800 . Véanse también los legajos de la administración del Pósito: 2673, 2675, 2677, 2678, 2679, 2680, 2682, 2683, 2684, 2685, 2688, 2662, 2664, $2686,2687,2688,2689,2690,2691,2692,2693,2694,2695,2696,2697,2698,2699$, $2700,2701,2702,2703,2704$. He intentado relacionar los legajos en orden cronológico.

7 Siguiendo las observaciones de Anes (1970), pp. 207-208. 


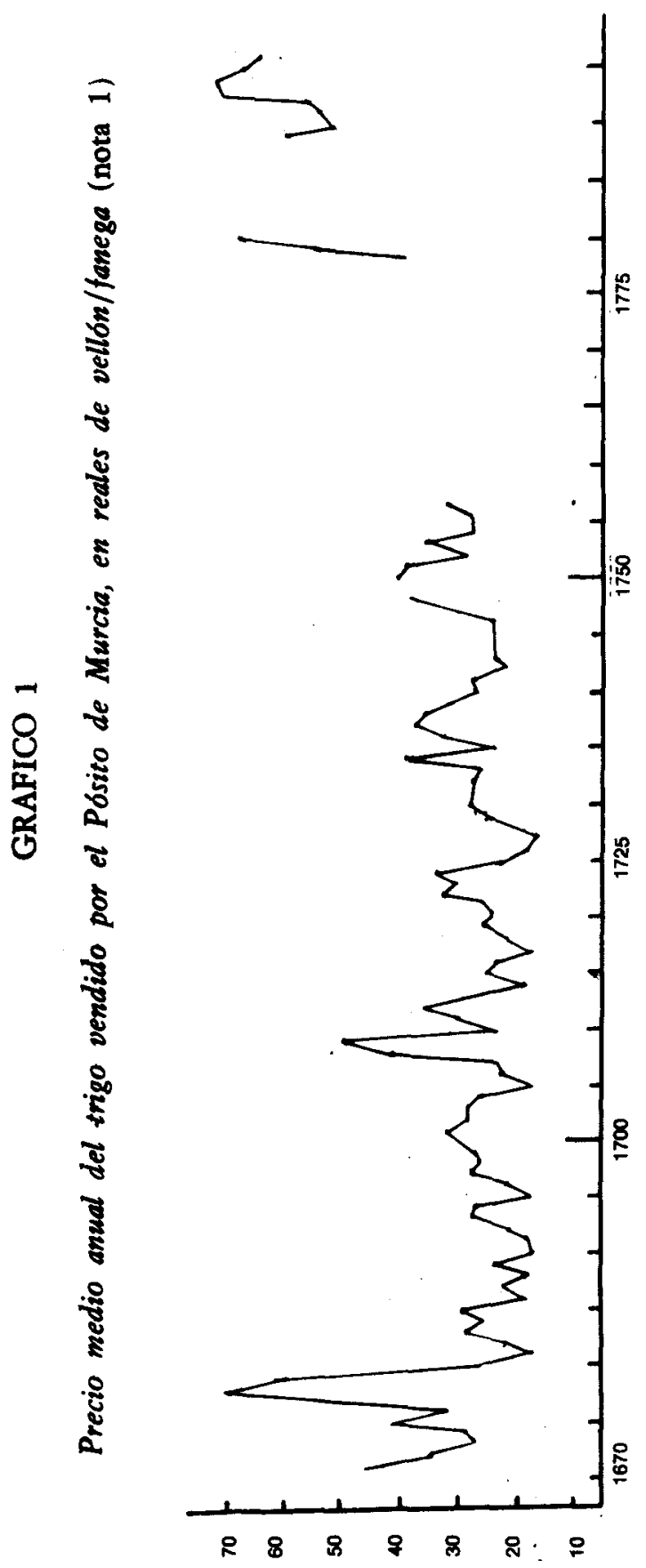


«con los procedimientos más sencillos» ${ }^{8}$. Se ha podido elaborar con este método una serie prácticamente continua de más de ochenta años, desde 1671 hasta 1756. Lamentablemente, para la segunda mitad del siglo es preciso conformarse con indicaciones para períodos más breves, $1778-80$ y 1789-96. Esta falta de datos no es tan insoslayable, como más abajo se verá, para poder completar los indicadores económicos; en todo caso, volvemos a repetirlo, su ventaja está en la solidez de los datos en que se funda.

Entre dos alzas: el siglo XVIII

Fortísima, violenta, la curva se mueve hacia arriba en los años setenta del xviI: en dos años, el precio del trigo - $y$ no se olvide que este precio es político, y que el Pósito lo vende en beneficio de la ciudadanía, sin afán de lucro- dobla su valor; de 36,2 reales/fanega en 1676 pasa a 54,58 en el año siguiente y a 72 reales en 1678 . Este valor nominal será superado sólo - ligeramente- en 1794: 72,12 reales por una fanega, 71,68 el año anterior; pero ahora se trata de un ciclo largo de alza, y no de los valores de tan sólo tres años.

Entre estos dos picos, una dinámica marcada por una serie de oscilaciones acentuadas, aunque menos extremas que las dos ya vistas: 1708-1709 representa una subida clara, debida a las incidencias de la guerra en los campos y en la economía de Murcia. Los precios alcanzan entonces 41,57 y 49,37 reales por fanega, muy por encima de la tendencia secular, y, una vez acabadas las operaciones bélicas, los precios vuelven a caer a niveles normales hasta los años 1722-1724, aunque en esta ocasión también los máximos son muy moderados. Ahora por el grano se pagan 32, 30, 34 reales, pero es un incremento de un 45,45 por 100 sobre la media de los cinco años anteriores.

Dos nuevas oscilaciones cíclicas se verifican en los años $1734-39$ y 1747-50. La primera consta de dos subidas, la una del año 34, a 39,62 reales/fanega, cuando doce meses antes costaba 27 -aumento en un 25 por $100-$, y la otra en 1736-38, con 34 reales de precio medio en los tres años. Los dos picos están, sin embargo, separados por un año de buenas cosechas y, por consiguiente, bajos precios: en 1735 , el trigo se vendió a 23,5 reales, es decir, un 41 por 100 más barato que el año de la subida anterior y un 35,33 por 100 por debajo de la media de los cuatro años de precios elevados.

La última oscilación bien documentada que se puede estudiar es la de los años $1747-50: 30,38$ y 40 reales por fanega $\longrightarrow$ con una laguna en el año 49-, lo que arroja una variación alcista del 56,15 por 100 sobre la media quinquenal anterior, excepcionalmente baja, por otra parte. Después la gráfica se in- 
terrumpe, quedando el testimonio de una primera, fulgurante, subida desde 1778 a 1780: 39,37 reales a 68,5 -aumento en un 73,99 por 100 en dos años-, y una última fluctuación desde 1790 en adelante, que, sin embargo, no es posible seguir por falta de datos fiables.

Estas variaciones cíclicas, que en la edad preindustrial son bastante más interesantes que los movimientos de larga duración, pues indican verdaderamente la influencia de los precios sobre la población ${ }^{9}$, se pueden comparar con las de otros estudiosos que han investigado las economías de distintos ámbitos geográficos peninsulares ${ }^{10}$. La curva murciana no tiene mucho que envidiar, en cuanto a violencia y frecuencia de las oscilaciones, a las de los lugares continentales como las expresa Anes, debido a que los suministros de grano procedían de zonas de Castilla la Nueva, como se comprueba por los documentos del Pósito ". Las coincidencias indican que nos hallamos ante una realidad más amplia que la puramente regional. Los precios de Murcia coinciden con las alzas castellanas de 1678, con las de Castilla la Nueva de 1682 1684; la misma subida se advierte en Granada y en Murcia en 1701. Lógicamente, es la misma pauta que Anes-Le Flem han determinado para Segovia, excepto que el último ciclo murciano del xvir dura hasta 1710 y la siguiente oscilación segoviana es más larga: 1698-99 hasta 1710-11. En Murcia, este ciclo abarca el período 1701-9. La subida de los años 1708-9 se da en Castilla la Vieja y Murcia a la vez; en Castilla la Nueva suben los precios en 1710, y en Murcia y en Granada, dos años más tarde. La subida de los años 1722-24, en cambio, es propia de Yecla y Murcia, y no se verifica en la zona continental ${ }^{12}$. Sí vuelven a coincidir los indicadores castellanos con los de la ciudad del Segura en 1730-1734 -cuando Yecla también sufre una fuerte alza-, pero luego Murcia vuelve a tener altos precios en los años 1737-38. Indudablemente, esto es un reflejo de la fase de malas cosechas de que habla Domínguez Ortiz, las cuales, empezando en 1734 , se extienden tres años más tarde por Extremadura y -esto es más grave para Murcia - por Castilla la Nueva. La década siguiente es en general buena, y se reafirma otra afirmación del mismo autor: la posibilidad de grandes cambios climáticos que afectaran a las cosechas a partir de mediados del xvirI.

El grave movimiento de precios de $1748-51$ es general en todas las zonas

- Anes-Le Flem (1965), p. 14.

- Como afirma Palop Ramos (1977), p. 34. tiva.

10 La bibliografía es muy amplia, y la que doy en este artículo no pretende ser exhaus-

" *La curva del precio del trigo presenta la forma atormentada que la caracteriza en la historia de los precios, hasta el último tercio del siglo xixw. Labrousse (1973), p. 80.

${ }^{12}$ El carácter local de «tres años continuos de esterilidad», según el cardenal Belluga, se debería a la relajación de las costumbres entre los murcianos. Pero si el diagnóstico fuera exacto, debería haber sido una exclusiva de este reino... Belluga (1720), p. 4. 
estudiadas, al igual que su repetición dos años después. Es probable, aunque los datos sean demasiado escasos para confirmarlo, que la subida de 1778-80 en Granada, Castilla la Nueva y Lorca tuviera su correspondiente manifestación en Murcia también. Y la coincidencia vuelve a ser total en la oscilación de finales de siglo, desde 1793 en adelante en Murcia, 1794 en las Castillas, y Granada en la misma fecha que Murcia. En 1801 fue «terrible hambre que afligio al reyno de Murcia», y la fanega de trigo llegó a costar 144 reales. La intervención de las autoridades eclesiásticas consiguió mantener los precios en $75-80$ reales, sin lo que «hubiera perecido la clase más numerosa» ${ }^{13}$. En el pasar de ciento veinte años sólo tienen en dos ocasiones los precios murcianos un comportamiento autónomo: la pequeña fluctuación hacia arriba en 1715-16 y la variación de $1737-38$, al parecer consecuencia de la de tres años atrás. Nos encontramos, pues, al estudiar la realidad de los precios en Murcia, ante una economía fuertemente relacionada con la escala nacional.

No será suficiente comparar la coyuntura murciana con la de la Península, sino que es posible refrendarla con la del mundo mediterráneo o con una parte de él: Gerona, Barcelona, Mallorca, Valencia ${ }^{14}$. Palop Ramos ha estudiado los precios de esta última ciudad y su dinámica concuerda, punto por punto, con la de la ciudad del Segura: máximas en los gráficos de precios en los años 1734, 1749-50, 1780 y 1792-93. Las mínimas coinciden igualmente, empezando por los bajos precios del trigo en 1727 y, luego, en 1732 —en Murcia la mínima es al año siguiente- y en 1742 - esta vez en Murcia el año antes, al igual que la mínima en Valencia en 1756 y aquí en el año anterior-. También hay una mínima relativa en $1790-91$ en ambas ciudades.

El paralelismo de estas dos series se explica dado el marco geográfico y los espacios económicos hacia los que gravitan; la dinámica de los precios en Murcia participaría entonces de un doble eje económico: el castellano, peninsular, y el mediterráneo, abierto a los transportes y suministros de más lejana procedencia. Indicativa de esta realidad es la coincidencia de las dos series de precios en la subida de 1737, que se da en Valencia y Murcia, pero no en las demás curvas que hemos observado.

Comparar los datos de la ciudad del Segura con los de otros marcos geográficos resulta más aleatorio por el método seguido para exponerlos. Están indicados en números-índice cuya base, siguiendo el método de Labrousse, ha sido fijada en el período 1726-40. Reducir la curva murciana a la misma periodización sería incorrecto, pues tales años abarcan los de las fluctuaciones de 1734 y 1737 . Por otra parte, dado que se trata de una extrapolación parcial y que la dinámica general es claramente alcista, y ya ha sido estudiada en sus pormenores, se ha construido la serie de índices, dejando bien claro que,

13 *Ilustraciones», en La lealtad murciana (1802), p. 8.

14 Palop Ramos (1977), pp. 29, 19 y 20. 
en el caso murciano, las fluctuaciones reales debieron ser bastante más acentuadas - lo que no queda reflejado debidamente por los elevados valores de los precios en el período base.

\section{CUADRO 1}

Indice de precios del trigo en Gerona, Barcelona, Valencia, Mallorca y Murcia. Reales de vellón por fanega

(Base: $1726-1741=100$ )

\begin{tabular}{|c|c|c|c|c|c|}
\hline Fecba & Gerona & Barcelona & Valencia & Mallorca & Murcia \\
\hline $\begin{array}{llllll}1726-41 & \ldots & \ldots & \ldots & \ldots & \ldots \\
1742-57 & \ldots & \ldots & \ldots & \ldots & \ldots \\
1758-70 & \ldots & \ldots & \ldots & \ldots & \ldots \\
1771-89 & \ldots & \ldots & \ldots & \ldots & \ldots\end{array}$ & $\begin{array}{l}100 \\
124,5 \\
148,5 \\
174\end{array}$ & $\begin{array}{l}100 \\
110,7 \\
138,4 \\
175,6\end{array}$ & $\begin{array}{l}100 \\
100 \\
130 \\
154,6\end{array}$ & $\begin{array}{l}100 \\
103,9 \\
144,9 \\
-\end{array}$ & $\begin{array}{l}100 \\
105,9 \\
\overline{193,2}\end{array}$ \\
\hline
\end{tabular}

Una vez más, se confirma la situación económica de Murcia: los datos son semejantes a los demás y el conjunto representa una realidad mediterránea francamente influida por el mercado continental, pero que disponía también de las válvulas de seguridad ofrecidas por la presencia de importantes puertos de mar; en el caso de Murcia, los de Cartagena y Alicante.

\section{Otras series, mismas dinámicas}

El trend de los precios del trigo del Pósito se explica en base a los precios del trigo comprado para abastecerlo, el llamado empleo del trigo. Era axioma generalmente aceptado que el Almudí no debía tener objeto de lucro, y no intentaba realizar beneficios económicos con su actividad; sin embargo, para el correcto funcionamiento - para la vida misma de la institución-, tampoco podía vender el trigo por debajo de su valor de compra, so pena de quiebra. Se observará que con la venta del grano al precio que tenía al momento del empleo, esto es, con rentabilidad cero, el Pósito perdía dinero, pues cuando distribuía trigo - generalmente en invierno- éste tenía un valor bastante más elevado que en la cosecha, cuando el Pósito lo había adquirido.

Los registros de la administración del Pósito ya citados proporcionan series de datos sobre los precios pagados por los abastecimientos del trigo, su cuantía en fanegas y el lugar de su procedencia. Es curioso que ninguno de estos datos haya sido usado con anterioridad por los investigadores de econo- 
mía en Murcia ${ }^{15}$. Los precios pagados por el trigo en cada empleo - se realizaba generalmente entre agosto y octubre- dan una indicación valiosísima sobre la dinámica de las cosechas, tal y como se explica en el gráfico 2. Tampoco ahora podemos disponer de series continuas, pero las que existen demuestran una total coincidencia entre ambas curvas de precios, la de las cosechas y la de los precios del Pósito. Dicho de otra manera, obtenemos la demostración de que la acción de las autoridades de la ciudad en materia de abastos está predeterminada por la calidad de la cosecha, y lo único que podía esperarse del Alholi -otro nombre, aunque menos corriente, de la misma institución- era que actuara en el estrecho margen de maniobra que le permitía la coyuntura económica.

Estando al gráfico 2, pésimas fueron las cosechas de los años 1678 y 79 , la de 1734 - de un año para otro el precio del trigo comprado por el Pósito subió en un 114,28 por 100-y las de los años 1748 en adelante hasta 1752 . El grano en este período llegó a tener un precio medio de 37,76 reales por fanega, contra los 22,12 de precio medio en los cuatro años anteriores, lo que significa una subida sostenida durante cinco años en un 70,7 por 100. Los efectos sobre las condiciones de vida de la población son fáciles de imaginar ${ }^{16}$. G. Lemeunier ha estudiado el producto de los diezmos en Mula para un período en parte contemporáneo al nuestro, y sus resultados concuerdan perfectamente con los gráficos del trigo que hemos obtenido para las cosechas: la imagen invertida de las curvas indica claramente la relación entre bajas cosechas y altos precios, y viceversa, por lo que podemos aventurar que estos casos particulares en el tiempo reflejan en buena medida la realidad de la coyuntura global murciana en la larga duración ${ }^{17}$.

\section{Tendencias $e$ indicadores}

El uso del índice-base a una serie de valores se aplicará con la desventaja de no dar un resultado directamente comparable con los de Anes o Hamilton o Palop, porque el período $=100$ no podría coincidir o, de lo contrario, se

" En realidad, sobre la acción económica del Pósito sólo existe un trabajo, citado en bibliografía, de Cremades Griñán $(1982,1983)$. Además de ser muy breve y de tono extremadamente divulgativo, es poco o nada fiable por una serie de fallos metodológicos. No se indica cómo han sido hallados ni calculados los valores de los precios, no se indica si se refieren a años naturales o agrícolas y, sobre todo, la serie es muy incompleta, a pesar de la existencia de datos en los registros del Archivo Municipal. Más riguroso el trabajo de Fernández Franco (1981), sobre la villa de Lorca, importante también por ser un lugar privilegiado en el abastecimiento de Murcia.

${ }_{16}$ Lamentablemente, y a pesar de su extremo interés, los precios de las cosechas sólo pueden tener un valor indicativo al estar referidos a distintos lugares de origen.

${ }^{17}$ La obra de Lemeunier (s. a.) es escasamente científica, pero es la única visión de conjunto de la historia del reino. 


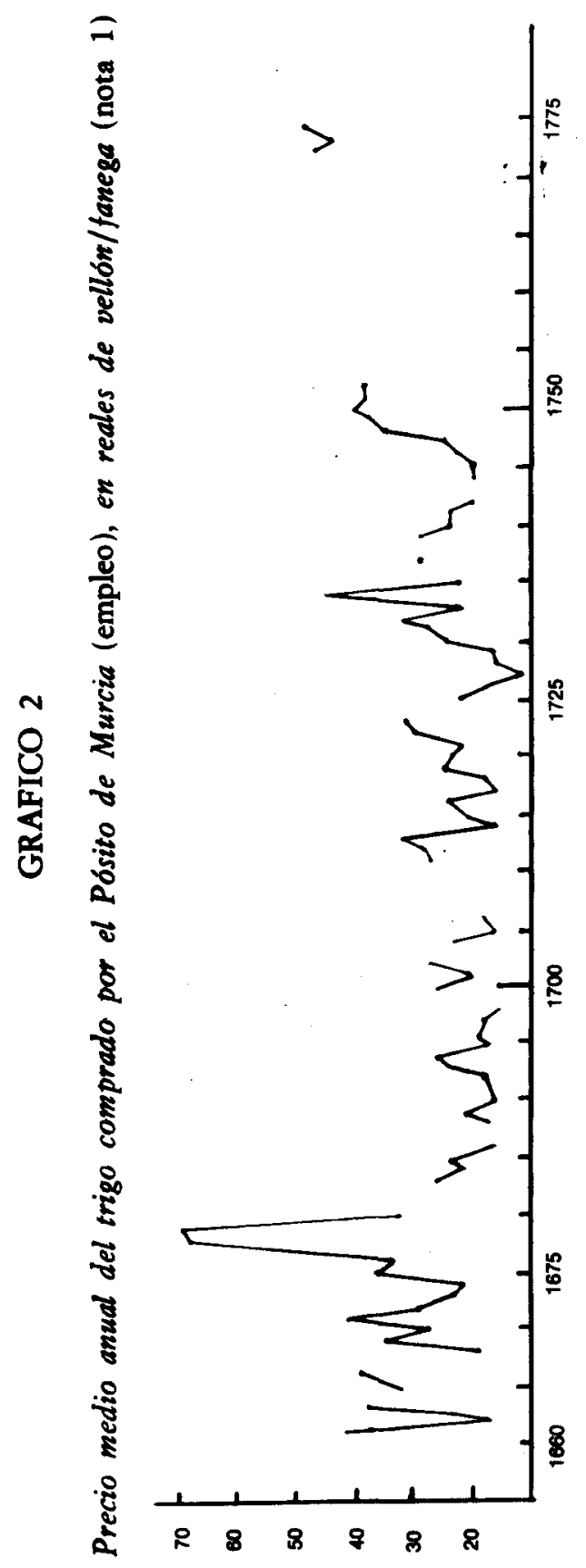


causarían distorsiones en las tablas de resultados. En el caso presente, el problema estriba en la elección de un período base, y es un problema doble, pues ha de ser aplicable a dos series distintas: precios del trigo vendido por el Almudí y valores del trigo en los empleos. Hemos elegido el índice, según dice Anes, como valor medio de períodos iguales, y cuyo resultado esté cercano a la tendencia central de la serie. En nuestro caso, el período más adecuado es el de 1731-39, que tiene un grado de coincidencia con los valores cercanos en las dos series de 0,97 y 0,95 , respectivamente, esto es, es muy fiable. Los resultados se dan en el gráfico 3 . La curva que se puede observar abarca casi cien años: 1661-1755. Dado el paralelismo entre las dos series, cada una por separado puede ser tomada por indicativa del desarrollo y fluctuaciones de la otra. Considerando la ponderación de los precios en base 100, se nota inmediatamente una situación general cíclica cuyas fases se aceleran en el transcurso del siglo. Los picos se sitúan en 1678-79, 1709 y, entre ellos, una etapa de fluctuaciones mucho menos violenta y muy por debajo del índice 100 . Entre 1709 y 1724 se verifica otra fase de marcadas oscilaciones y otra de igual duración que llega hasta 1738, con índice 110,6, y que es ligeramente más corta, doce años en lugar de catorce de los ciclos anteriores.

Sin embargo, la primera parte de nuestro estudio está caracterizada por una onda más larga, treinta años, y también mucho más violenta, alcanzando un máximo de 235,3, lo que representa una cima histórica, bastante superior incluso a las alteraciones de finales del xviII, que coinciden con las generales de toda España, pero que alcanzan un límite máximo de 223,3. Sobre este último período del siglo - 1770 hasta 1800 - sólo podemos conjeturar una fase de alza sostenida, aunque no tengamos datos de primera mano sobre la entidad de los movimientos.

A título puramente indicativo, y puesto que se puede comprobar que la curva de los precios del trigo del Pósito y la de los precios del pan en Murcia son semejantísimas, podemos tomar a la segunda por indicadora de la primera; esto, que es un ejercicio de extrapolación puramente en vía de hipótesis, nos indica (gráfico 4) dos fases de tres movimientos dentro de una sola dinámica alcista. 1769-85: entre estas dos máximas, un período de fluctuaciones moderadas, sin un signo definido; pero de 1785 a 1798 las oscilaciones se hacen más acusadas $\mathrm{y}$, sobre todo, tienden hacia arriba.

Para dar el análisis global de la coyuntura econúmica de Murcia a caballo entre el xVII y el xvirI se han reducido los valores al índice 100 puesto por Hamilton ${ }^{18}$, lo que arroja unas cifras bastante indicativas para este periodo: $1726-1750=25,6$ reales, que se acercan bastante al valor medio central del trigo elegido para realizar el gráfico 3. Las diferencias saltan a la vista

${ }^{18}$ Hamilton (1969), p. 184. 


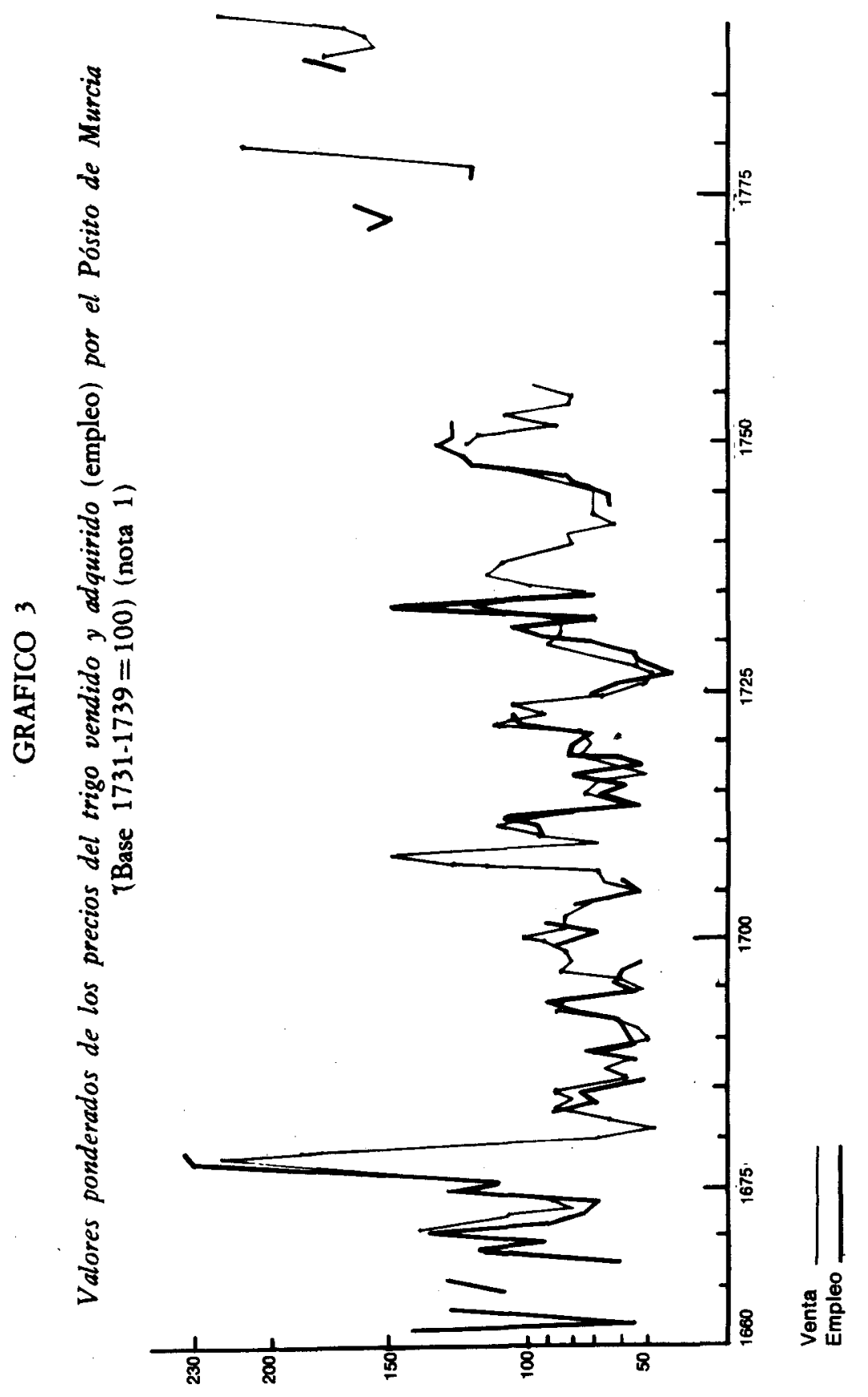




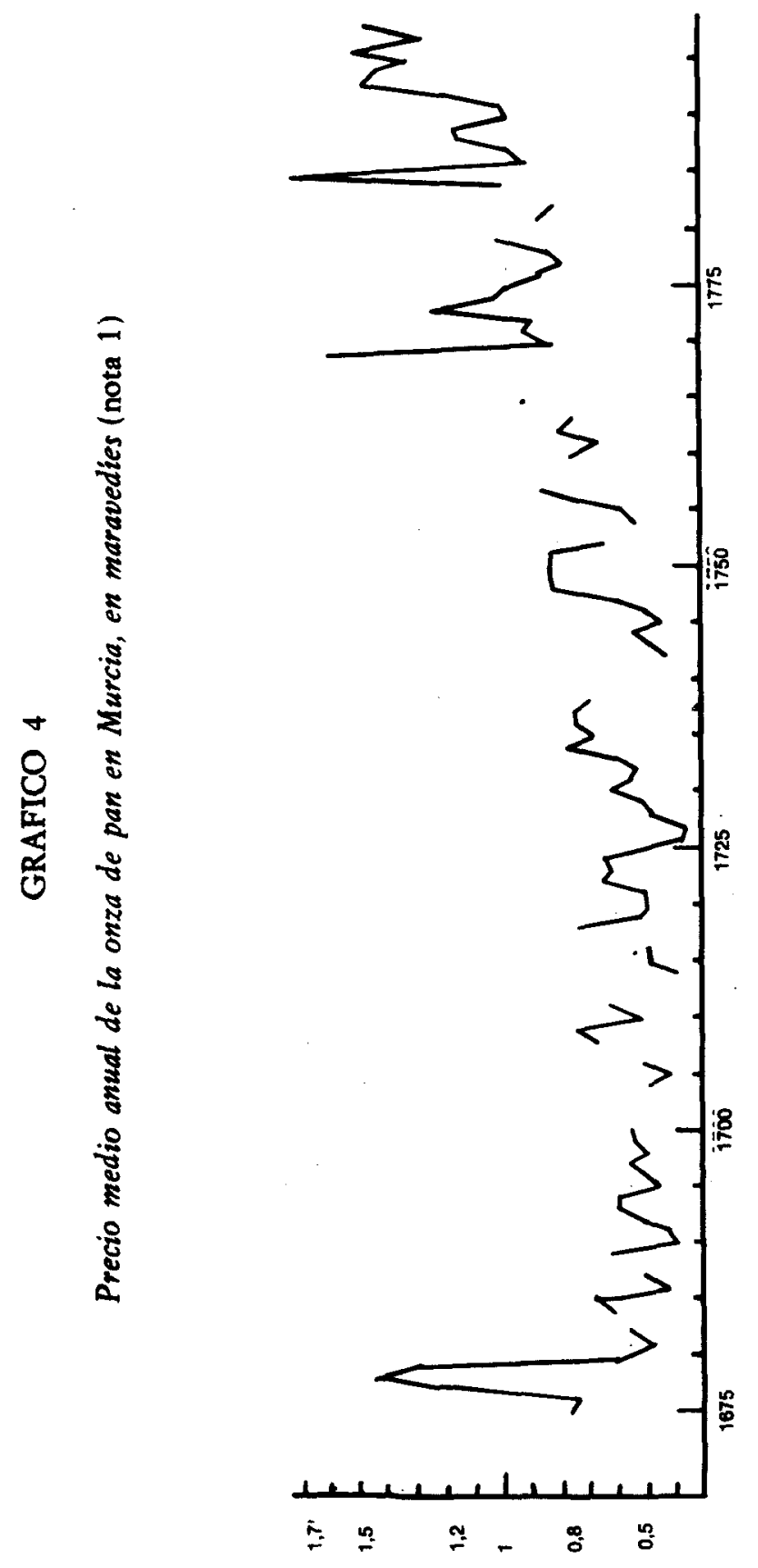


(cfr. gráfico 5): no sólo la fluctuación de 1676-80 es más acusada en Murcia que en Castilla, sino mucho más que en Andalucía y Valencia -índices 197,9, $191,3,177,7,102,3$ - Esta última ciudad podía contar con el mar y con sus vías de cemercio para paliar sus necesidades, cosa que Murcia parece no haber conseguido satisfactoriamente. También son más altos los mínimos de $1771-75$ en Murcia que en cualquier otro lugar: 184,7, 155,3, 135,8, 143,3 son los valores indice. En el quinquenio siguiente, la diferencia aún se hace mayor. El siglo se cierra con unas cifras que, dentro de la tónica general, se han disparado en Murcia: en 1791-95, el índice alcanza 229,8, mientras que en Castilla la Nueva no pasa de 200,7, en Andalucía de 208,4 y en Valencia es de 188,5 . El soberbio trabajo de M. C. Melendreras Gimeno hace una luz esclarecedora sobre la situación finisecular en Murcia y sus repercusiones sobre los precios. Los valores ponderados, en diez años, alcanzan índice 225, y en los últimos quince años de la centuria el precio de la fanega de trigo ya no estará jamás por debajo del indicador 137 , valor excepcionalmente bajo que corresponde al año de 1787. ¿Qué ha habido entre estos dos momentos, entre estos dos estremecimientos? También en la baja se notan las peculiaridades murcianas.

Los gráficos se encabritan, pero a partir de $1689-90$ bajan con tendencia general y regular. Otra vez Murcia destaca, pues ahora sus indicadores descienden más que los de fuera: valor 69,06 contra 88,4, 71,8 ó 78,9 en Castilla, Andalucía y Valencia. A partir de ese momento, y hasta 1731, los índices quedan por debajo de 100 o apenas los rozan en 1725; en las otras curvas consideradas, las dinámicas son menos lineales y tienen fluctuaciones más acusadas. Sin embargo, también es en Murcia donde se registra el mínimo histórico, 1726-30, con un índice de 68,75 , no igualado en ninguna de las otras zonas estudiadas. Desde esta fecha, las oscilaciones empiezan a hacerse sentir, violentas, en nuestro territorio: del mínimo se pasa, cinco años más tarde, a 115,62 , se baja a 83,2 en la década siguiente, para luego subir a 125,78 y a 150 de índice en 1751-55, desde donde se emprende otra vez una bajada a 111 y 116,87 en los diez años siguientes. La oscilación de 1751, por cierto, sólo es comparable con la de Castilla la Nueva, donde ofrece un valor ligeramente superior: 151,2, según Hamilton. Faltan datos para explicar el porqué de estas oscilaciones, al menos en los archivos de la capital. Tal vez la respuesta esté en el tráfico marítimo, y esto abre un nuevo campo de estudio a los investigadores de la zona.

Tras estas comparaciones es posible determinar tres grandes fases en los precios de los granos en Murcia: subida hasta los años ochenta del xvII, estancamiento por debajo del índice 100 hasta mediados del siglo sucesivo y, por fin, una subida imparable, y esta dinámica sigue en sus rasgos la tónica 
GRAFICO 5

Valores ponderados de los precios de los trigos (Base $1726-1750=100$ )

(Véanse Hamilton, War and Prices, cit., p. 184, y nota 1 )

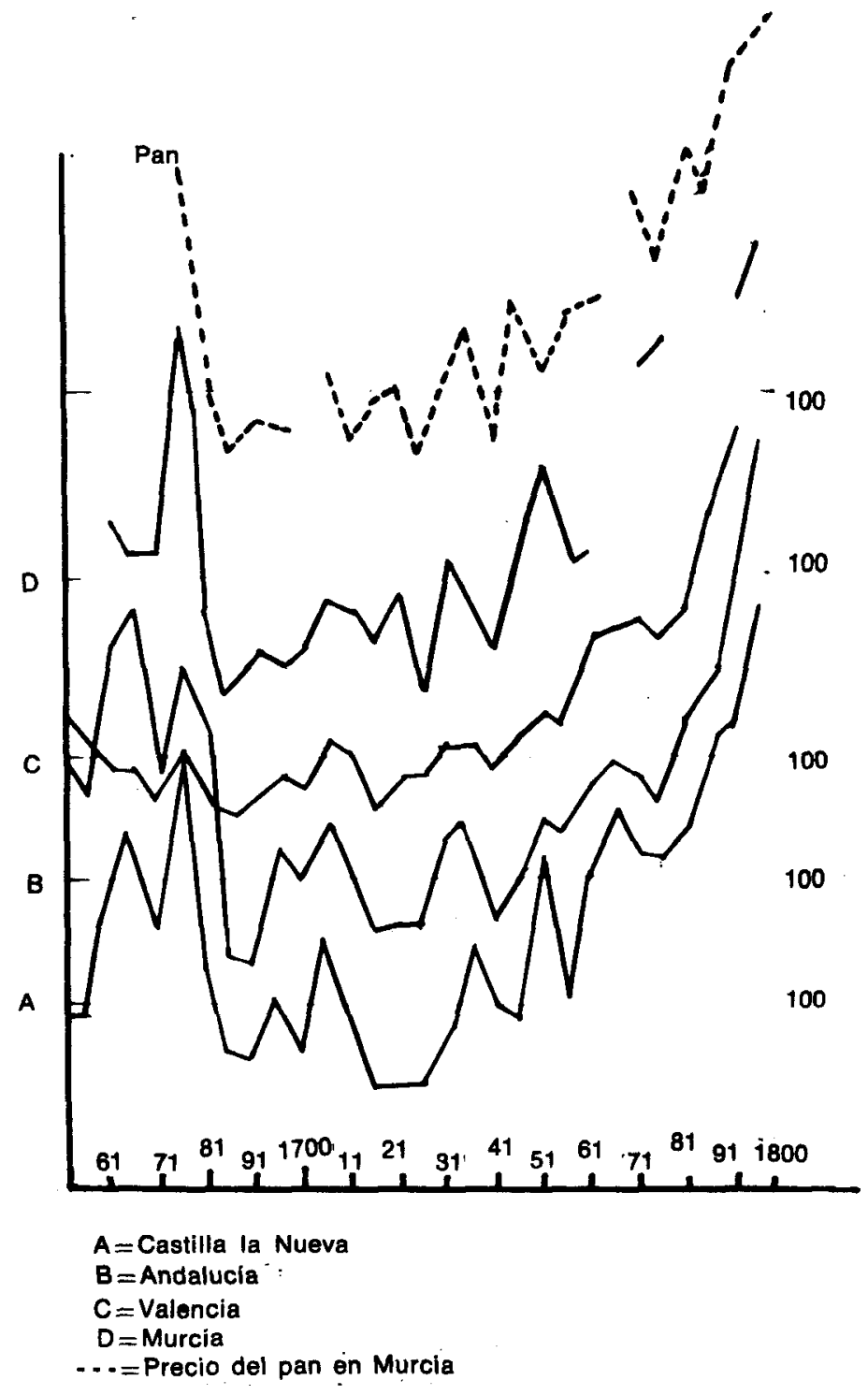


general española, pero con valores más acentuados. Sin embargo, aún no se ha completado el análisis de los datos.

Hasta el momento no se ha escrito una sola vez la palabra crisis. Sería muy posible emplearla en cada ocasión en que topáramos con un valor máximo de los precios, y al igual calificar de coyuntura favorable la presencia de cifras o índices bajos. Pero estamos trabajando con indicadores indirectos; los precios del trigo no dan la indicación de su impacto sobre la sociedad, que es el verdadero centro de interés. Calificar de favorable la situación de varios años consecutivos porque los indicadores numéricos son bajos sólo tiene sentido porque suponemos que los valores altos de la misma serie debieron tener efectos demoledores sobre la vida de la población. Coincidiendo con una época de bajos precios de trigo, en 1724 la libra de pan de 14 onzas de peso llegó a costar 6 maravedíes; pero el salario medio de un jornalero no alcanzaba los 3 reales diarios, o traducido en pan 17 libras, o sea, menos de 8 kilos de pan. Entonces las coyunturas favorables sólo son, para los grupos sociales mayoritarios, un alivio en condiciones de vida siempre precarias.

Más fácil es hacer luz sobre los beneficiados por la fortuna, quienes ocupan las capas privilegiadas de la sociedad. Está muy claro que, aceptando el modelo teórico de Fernández de Pinedo ${ }^{19}$, al ser percibidos los productos agrícolas en concepto de rentas por los propietarios de tierras, los beneficios están asegurados incluso en caso de bajos precios. Esto significa entonces que las coyunturas de $1670-80,1709-10,1721-23,1734-38$ y 1747-50 debieron ser años de beneficios espectaculares para los rentistas. La segunda parte del siglo, con una tendencia alcista cada vez más sostenida, debe haber marcado la pauta para el afianzamiento en el dominio de la aristocracia económica murciana. El mecanismo de percepción de la renta fondiaria en especies es indicado por Domínguez Ortiz como proceso de afirmación de la clase dominante. Se tratará ahora de investigar si en Murcia se dan las condiciones formales -estudiando las normas de arrendamiento- para establecer las fases de desarrollo del capitalismo agrario en la zona.

" Fernández de Pinedo (1980). 


\section{CUADRO 2}

Precios medios anuales del trigo vendido por el Pósito en Murcia, en reales vellón/fanega, por año agricola

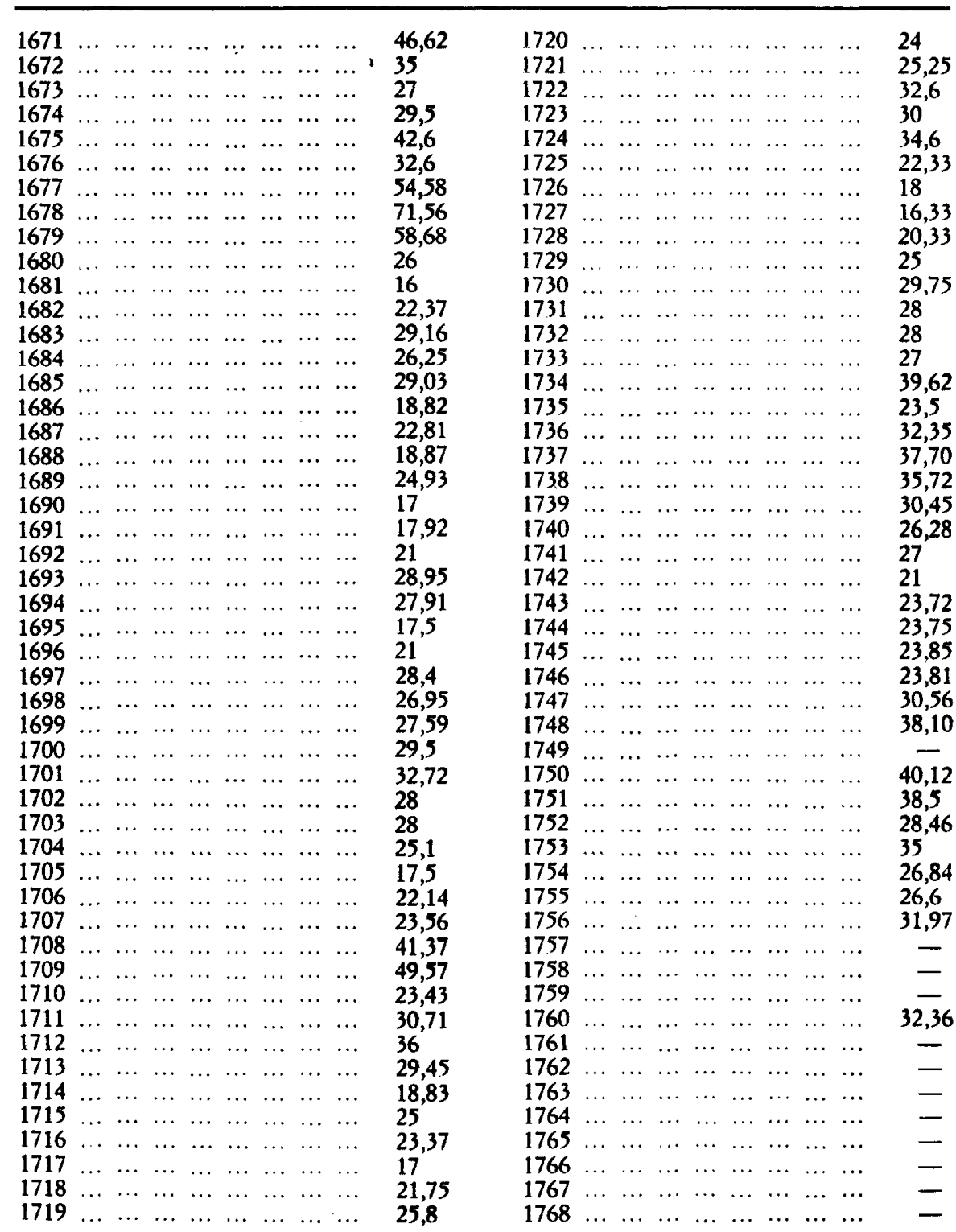




\section{(CUADRO 2 (Continuación)}

\section{Precios medios anuales del trigo vendido por el Pósito en Murcia, en reales vellón/fanega, por año agricola}

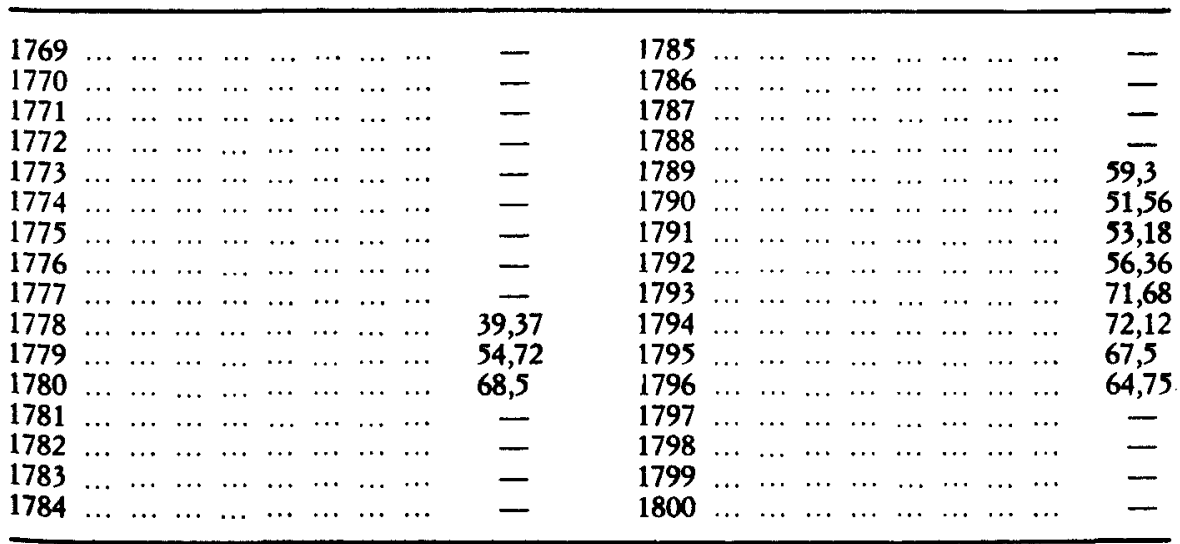

\section{BIBLIOGRAFIA DE LAS OBRAS CITADAS}

Anes, G. (1968): «Los Pósitos en la España del siglo xviII», en Moneda y Crédito, 105.

ANEs, G. (1970): Las crisis agrarias en la España moderna, Madrid.

Anes, G., y Le Flem, J. P. (1965): aLa crisis del siglo xvil», en Moneda y Crédito, 93.

Bellugh, L. (1720): Edicto y breve carta..., Murcia.

Castillo de Bobadilla, J. (1704): Politica para corregidores, Amberes.

Cremades Griñán, C. M. (1982): «Gastos municipales en el Concejo de Murcia», en Anales de la Universidad de Murcia.

Cremades Griñ́n, C. M. (1983): «Administración y arrendamiento del Pósito de la ciudad de Murciaw, en Actas de las Segundas Jornadas de Metodología y Didáctica de la Historia, Universidad de Extremadura.

Cremades Griñ́n, C. M. (1984): Alimentación y consumo de la ciudad de Murcia durante el siglo XVIII, Murcia.

Domínguez Ortiz, A. (1976): Sociedad y Estado en el siglo XVIII español, Barcelona.

Espinalt, B. (1778): Atlante Español,. Madrid; ed. fac. (1981), Murcia.

Fernández de Pinedo, E. (1980): Historia de España, VII, Barcelona.

Flores Arroyuelo, F. J. (1977): «Noticias sobre el Pósito de Murcia en la encrucijada de los siglos XVIII y XIX*, en Murgetana, XLVIII.

GIMÉNEZ López, E. (1981): Alicante en el siglo XVIII, Alicante.

Grupo 75 (1977): La economia del Antiguo Régimen, Madrid.

Hamilton, E. J. (1969): War and Prices in Spain 1651-1800, Nueva York.

Hernández Franco, J. (1981): aEl precio del trigo y la carne en Lorca*, en Murgetana, 1.

LABrousse, E. (1973): Fluctuaciones económicas e bistoria social, Madrid.

La lealtad murciana (1802), Murcia.

Lemeunier, G. (1976): «La part de Dieu. Recherches sur la levée des dîmes au diocése de Murcie d'aprés les visitas de tercias», en Melanges de la Casa de Velázquez, XII. 
Lemeunier, G. (1983): «La coyuntura murciana: población y producción en el siglo de orow, en Cuadernos de Historia, 10.

LEMEUNIER, G. (s. a.): "Conquista agrícola y feudalismo desarrollado", en Historia de la región murciana, Murcia.

L,YNCH, J. (1976): España bajo los Austrias, Barcelona.

Melendreras Gimeno, M. C. (1970-1971): «La economía murciana durante la Guerra de Independenciaw, en Anales de la Universidad de Murcia.

Melendreras Gimeno, M. C. (1980): «Contribución al estudio cuantitativo de la evolución diezmal en Murciaw, en Anales de la Universidad de Murcia.

Meuvret, J. (1971): Les prix des céréales dans la France méditerranéenne, París.

Novísima Recopilación (1805).

Olivares Galván, P. (1976): El cultivo y la industria de la seda en Murcia en el siglo XVIII, Valencia.

Ortuño Palıo, M. (1979): La vida en Yecla en el siglo XVIII, Murcia.

Palop Ramos, J. M. (1976): El litoral valenciano y el avituallamiento de Madrid, Valencia.

Palop Ramos, J. M. (1977): Fluctuaciones de precios y abastecimiento en la Valencia del siglo XVIII, Valencia.

Pérgz Aparicio, C. (1975): «El trigo y el pan en Valencia, 1700-1713w, en Cuadernos de Historia, 5.

Plaza Prieto, J. (1976): Estructuras económicas de España en el siglo XVIII, Madrid.

Pragmática que $S u$ Magestad manda publicar en orden al precio, y tassa, que han de tener los granos que se compraren, y vendieren, en estos reinos (1699).

Ramos Vidal, J. A. (1980): Demografía económica y sociedad en la comarca del bajo Segura durante el siglo XVIII, Orihuela.

Real pragmática por la qual Su Magestad se sirve abolir la tasa de granos, y permitir el libre comercio dellos en estos Reynos (1765).

Real orden para informar sobre los pósitos de trigo que bay en las ciudades españolas (1679).

Real provisión de S. M. para que el trigo que se sacare de esta ciudad sed quedando en los lugares de su reyno el necessario para su abasto (1677).

Real provisión para que se remitan las ordenanzas de los pósitos para su buen gobierno (1699).

Real provisión para que el trigo que de orden de esta ciudad se bubiere comprado y se condujere a ella para su abasto, no se lo detenga, cuiten ni embarquen (1678).

Real provisión para que la ciudad de Murcia pueda enviar a comprar el trigo, zebada y zenteno que necesitare para su abasto y no se le embarace (1679).

Keal provisión para que no se impida a Murcia la compra y conducción de trigo en los lugares de su reyno (1686).

RINGROSE, D. (1972): Los transportes y el estancamiento económico de España, 1750-1800, Madrid.

Serra Rurz, R. (1981): Estudios de bistoria de Murcia, Murcia.

Vilar, P. (1978): Cataluña en la España moderna, Barcelona. 